\section{The place of health innovation in space to improve the lives of earthlings}

\author{
Brigitte Godard*
}

General Practitioner \& Specialist, Medical Biology, Incharge of Clinical Research, MEDES, Astronaut Doctor, European Astronaut Center, Cologne, Doctor, MEDES, Institute of Space Physiology of Toulouse, IMPS - MEDES, BP 7440431405, TOULOUSE Cedex 4, France

\section{Summary}

For over twenty years, following the creation of space stations, MIR first and then the ISS (International Space Station) men (3 to 6) live and succeed each other continuously about 300 - $400 \mathrm{~km}$ of altitude to make scientific experiments. For this reason sending men into space has become an activity "almost banal or regular "but this remains potentially a very dangerous environment for the adapted manon Earth and thus requires medical monitoring to ensure the health of astronauts and the persistence of their ability during their mission. In general, the medical benefits on Earth of space conquest go far beyond envy and the need for man to discover the cosmos but to develop many tools medicines to also offer solutions for all living beings on Earth!

\section{Introduction}

This article is the result of a presentation given by Dr. Brigitte Godard on October 3, 2018 as part of the 16th National Study Days of Nursing Directors in Toulouse.

Space medicine is a very vast subject ... indeed since it concerns all human medicine adapted to the very specific space environment. Space is a particularly aggressive environment for the human body adapted to live on Earth. For more than twenty years, following the creation of space stations, MIR first and then the International Space Station (ISS) men (3 to 6) live and succeed each other permanently at about 300 $400 \mathrm{~km}$ altitude to do scientific experiments. The purpose of this intervention was to explain what space medicine really is through its experience as an astronaut physician and to understand how this medicine can be useful and have spinoffs for Earthmen.

Even though sending men into space has become an activity "almost banal or regular" space remains potentially a very dangerous environment for the adapted man on Earth and thus requires medical monitoring to ensure the health of astronauts and the persistence of their ability during their mission. Therefore, it is necessary to really understand the dangers encountered by the astronauts to be able to minimize the risk of becoming sick in space.

\section{More Information}

*Address for Correspondence: Brigitte Godard General Practitioner \& Specialist, Medical Biology, Incharge of Clinical Research, MEDES, Astronaut Doctor, European Astronaut Center, Cologne, Doctor, MEDES, Institute of Space Physiology of Toulouse, IMPS - MEDES, BP 7440431405, TOULOUSE Cedex 4, France, Tel: + 0033 (0) 649329256; Email: godard_brigitte@orange.fr

Submitted: 05 August 2019 Approved: 26 August 2019 Published: 27 August 2019

How to cite this article: Godard B. The place of health innovation in space to improve the lives of earthlings. Ann Civil Environ Eng. 2019; 3 : 045-053.

DOI: dx.doi.org/10.29328/journal.acee.1001017

Copyright: @ 2019 Godard B. This is an open access article distributed under the Creative Commons Attribution License, which permits unrestricted use, distribution, and reproduction in any medium, provided the original work is properly cited

Keywords: Astronaut; Gravity; Radiation; Telemedicine; Confinement; Chronobiology; Aging; Sedentary; Satellite

D) Check for updates
The presentation was divided into three main parts: the first one made it possible to take stock of the work of astronaut's doctor (comparing with the work of a classical general practitioner). In this first part the goal is really to show that danger in space must be anticipated by first selection of the good candidate before the flight (Godard and Weerts), and a perfect follow up to be able to detect a various condition which may become more complicated in space. Of course the goal of the flight surgeon is to assume the safety of the astronaut to ensure his health maintenance and well being.

When we compare the work of the general practitioner and the one of the flight surgeon as a first glance they have the same goal: healthy, happiness and well being. But looking at it carefully we see all the difference in between a patient coming to his doctor to receive a treatment (non necessarily medicament but help from his physician) and the astronaut. He hasne't chosen the physiscian and he just wants to fly whatever happen.. like pilot usually the physiscian are not the favoite ones of the pilot because the physician can be a stopper for his flight.

Of course when the relation is well established in between the astronaut and the flight surgeon, we can see it in a different way. Both the astronaut and the physician work to the same 
goal make sure that the astronaut can fly. The astronaut must trust his physician and give him all needed information which might help the physician in finding and doing the right exam to complete the folder of the astronaut and "make him fly".

A very big difference in the two jobs is that the general practioner is basically alone (he can send the patient to a specialist but usually he will do only when he cannot solve the issue alone. A flight surgeon has to follow the rules established by all the partners and present the astronaut before his flight to the international partner. He is never alone even at the European level, he will have help from the other colleagues, a deputy in the best case and helped for a technical side by the biomedical engineers.

A second part allowed to understand the specific risks incurred by astronauts and therefore their surveillance. In this chapter a review of the main concern system by system will be reviewed in a first part. Of course all cannot be fully describe and furthermore it has been describe in many papers and space book [1,2]. In a second part of this chapter some generics countermeasure to avoid or treat the potentials alteration of the human body in these main areas of concern will be briefly discussed.

The third part showed the resulting applications of this space activity for the Earthmen.

Nowadays we cannot send astronauts to space just to enjoy the space. It becomes more and more obvious that the space help in many field either to develop new technologies which will be really useful to the humanity on earth. A very good example is i some isolated area, a physician even if not available can be replace by the nurse with the used of remote medicine and recent experiments have shown surgery can be really well performed by a non specialist with telerobotic operations. Teleechography will be the good example shown in this article which allow the astronaut to be checked and using the help of remoted person on the ground.

Brigitte Godard held the position MEDES (Institute of Space Medicine and Physiology of Toulouse, (Subsidiary representing the medical part of the CNES, French Space Agency) astronaut doctor at the European Space Agency in Cologne from 2010 to 2017 and took in charge a certain number of astronauts including 3 selected young people in 2009, Luca Parmitano, Samantha Cristoforetti and Thomas Pesquet.

\section{Astronaut physician function}

It is true that the function of astronaut's doctor is very peculiar. First of all, there are few doctors in this position, 3 in Europe when B Godard arrived in Cologne. Here is a brief outline of the major differences between a general practitioner and the astronaut doctor. First of all, it may surprise but the astronaut doctor is overwhelmed with only one patient! He will follow this astronaut for 3 years, i.e. 2 years before his mission, 6 months at present during his 6-month mission aboard the ISS and finally 1 year after his return.

This can make general practitioners smile and B Godard knows what she is talking about since she has held this position of general practitioner for 7 years, replacing general practitioner in rural sector mainly but also in Paris. In general medicine in the countryside the doctor will have to pass from a baby to a senior in the meantime adults coming with very different pathologies not to mention the emergency call for a car accident or psychiatric emergency, hanging for only mentioning a few ...

And do not talk about influenza epidemics where the phone rings constantly and the doctor will travel the farm campaign in the cottage.. So in the end he will have consulted a number closer to 30 or $40-50$ patients.

One of the big differences is also that the astronaut is not a patient, he is more followed as in the field of occupational medicine in terms of aptitude for his work. While in general medicine indeed a patient is really requesting and consults for a specific need while in fact the astronaut is in consultation as part of his aptitude. And of course the work of astronaut doctor is a real collaborative work within a multidisciplinary and international team. Collaboration is extremely important and all activities must be carried out jointly and from documents prepared and reflected by all international partners (NASA, CSA, ESA, JAXA, Russians) [3]. Obviously, some tasks are specific to each country, but globally each astronaut sent to the space will be presented medically to the international team (medical office with a senior experienced doctor in the space sector representing each partner country) who will judge his medical condition and will deliberate and give a "GO or NO GO" for this mission. It may therefore happen that the astronaut is declared unfit for a transitional period pending either the resolution of the medical problem or the completion of a number of additional medical investigations that will receive acceptance from the medical office of all partners.

As attempts to illustrate these two drawings, in general medicine patients waiting their turn, in space medicine, it is several doctors but not only different trades that will revolve around a single astronaut to build his record and allows him to live his mission in Space. All this concerns the pre-flight stage (Figure 1).

When the astronaut is on a mission aboard the station then the work of the doctor is moving towards a remote medicine. Obviously, an astronaut is selected according to strict and precise criteria that make him already very healthy [4].

The doctor assigned to this astronaut will become on a medical level his unique or almost unique medical interlocutor. If necessary the doctor will call the rest of the team but private medical consultations will be performed once a week for 15 


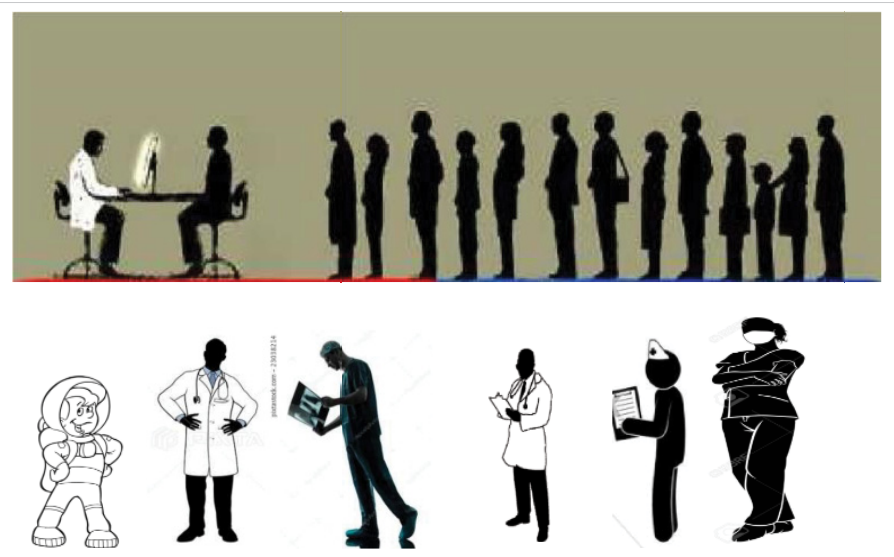

Figure 1: As attempts to illustrate these two drawings, in general medicine patients waiting their turn, in space medicine, it is several doctors but not only different trades that will revolve around a single astronaut to build his record and allows him to live his mission in Space.All this concerns the pre-flight stage.

minutes if all goes well (private communication between the doctor and his astronaut). During this consultation, will be reviewed the essential points, sleep, physical state (symptoms ...), diet, psychological state, work, relationship with the team. And any other point that the doctor or his astronaut consider necessary to approach for the smooth running of the mission or the proper maintenance of the astronaut's health.

This work remains a team effort, during the stay aboard the ISS, the doctor with the team of biomedical engineers goes daily to follow the progress of the mission and manage thanks to this team the schedule for it remains compatible with a normal activity and respecting medical desideratas (example not to do sport immediately after the meal..) (Figure 2).

This console activity as shown in the photo is essential, it also ensures that the astronaut is in shape, harmony reigns within the station in the team...

The doctor can exchange by email with the astronaut and thus not wait for the next Private Medical Conference (PMC).

Then in the post-flight phase, the most important step will be to find the astronaut for the moment in the steppes of Kazakhstan and bring him back to Cologne by providing him the best possible care given a relatively long stay in space and to which is added the traumatic event of the landing. This

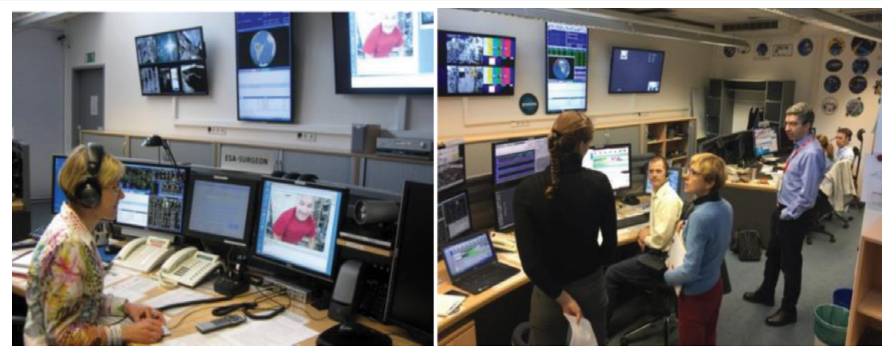

Figure 2: This work remains a team effort, during the stay aboard the ISS, the doctor with the team of biomedical engineers goes daily to follow the progress of the mission and manage thanks to this team the schedule for it remains compatible with a normal activity and respecting medical desideratas (example not to do sport immediately after the meal ..) work is ultimately closer to the conventional doctor's job or eventual emergency care and follow-up plus rehabilitation. Much would be said about these different phases of flight but this should be the subject of another communication to avoid overloading this text.

\section{Space environment very hostile to humans}

The second part of the paper focused on the space environment and therefore the effects on astronauts. What are the dangers of this environment for man and how to guard against it? $[5,6]$.

The dangers are therefore directly related to the new environmental conditions (news for a Terran who leaves the Earth and goes into space). As already mentioned above, the station gravitates at $300-400 \mathrm{~km}$ altitude and at this altitude, among the most unusual factors we find the absence of gravity, a much higher radiation rate than on Earth, the life in confined environment and changes in circadian rhythms. Many other factors are identified, extreme conditions of temperature and pressure outside the station but to be taken into account for extra-vehicular trips.

Exposure to space radiation is one of the main challenges for future long-term space and interplanetary space missions. Many uncertainties remain, especially to quantify the risk of radiation-induced cancer.

In the 1960s, we generally learned 3 things: 1- during short missions in low orbit the received radiation dose is around $0.17 \mathrm{uGy} / \mathrm{min}, 2$ - the passage in the SAA zone (South Atlantic anomaly ) dramatically increases exposure and probably by a factor of 625, 3- unpredictable solar particles can dramatically increase the total dose of radiation received [7].

In the 1980s the technique of in situ hybridization (FISH) (a method that will explore genetic changes induced on DNA) has allowed a considerable advance and thus replaced the Giemsa (staining) gradually. This technique is more accurate because it uses fluorescent probes that can isolate chromosome portions to target areas where translocations have occurred, and chromosome exchange as well as centromere and telomere localization. However, despite the technical progress, this has not resolved and allowed to conclude when radiobiological effects and their impact on astronauts.

Epidemiological studies of populations exposed to ionizing radiation (primary XRays or gamma rays) show an increase in the incidence of degenerative tissue damage with, for example, cataracts and cardiovascular diseases (atherosclerosis). The underlying mechanisms are still poorly understood but involve oxidative and inflammatory damage as well as direct deleterious effects on the tissues [8].

Onboard astronauts receive an average of $80 \mathrm{mSv}$ for a maximum of 6 months of solar activity (when there is a maximum of sunspots and the maximum of solar magnetic fields to deflect particles. 
This value goes to $160 \mathrm{mSv}$ during the period of minimum solar activity for a stay of 6 months too.

Although the type of radiation is different on Earth, $1 \mathrm{mSv}$ of radiation in Space is equivalent to the average dose received for three chest x-rays. On Earth we receive an average of 2 $\mathrm{mSv}$ each year of all radiation in general [9].

During EVAs (extra-vehicular exit), astronauts wear readings before and after each EVA.

The stakes for a flight to Mars regarding radiation are: there is no magnetic field on Mars as on Earth to protect cosmic rays and solar jets. The Marsian atmosphere is also less than $1 \%$ as thick as that of the Earth. These two factors make Mars a very vulnerable planet for space radiation.

Microgravity also has an impact on all the physiological systems of the human body.

The probably most studied effect since the beginning of the flights is that on the heart and the musculoskeletal system.

Indeed themostimportanteffectsareamusculoskeletalmelting [10], with osteoporosis greater than that of postmenopausal women, loss of $1 \%$ bone per month for an astronaut while this loss is about $1 \%$ of bone per year at menopause. These values of course change depending on the individual and the location as shown in the following diagram:

It is indeed the carrier bones that are most affected (in bold in this drawing).

Effects on the vascular system [11] show stiffness of the vascular wall, atrophy of the heart muscle with some degree of heart failure, and orthostatic intolerance to return to Earth.

The harm of the space which is equivalent to that of
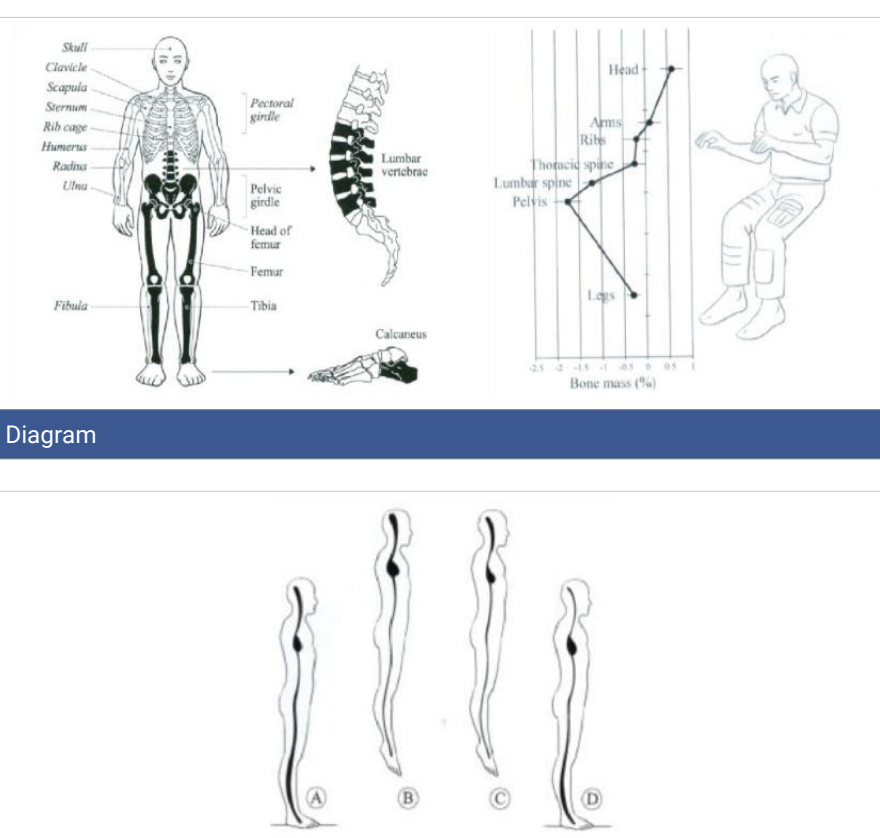

seasickness or simply motion sickness.. Affects the first days $30 \%$ to $50 \%$ of the astronauts but does not last long 2 or 3 days at the maximum maximum one week. Characterized by dizziness, nausea fatigue and can go to vomiting. He is well warned by drugs. And does not pose too much problems for flights of 6 months which was not the case at the beginning of shuttles flights. These lasted 8 to 10 days and of course the astronaut who was sick a week saw all his activity reduced on board and if he had an EVA was seen most often unable to achieve it.

It is explained by a conflict of sensory afferences. Indeed it is the same thing in the context of the motion sickness, the different stimulations coming from the vision or from our sensors situated in the inner ear (vestibule and which make it possible to evaluate the position of the body and the head in space will have different information even contradictory that will be at the origin of this evil. It is one of the explanations there are at the moment other hypotheses but nothing is yet proved [12].

On the neurological level there are changes in writing, concentration and also sleep disorders [13]. These are not only the result of microgravity, but also the many alarms that are often triggered at night, overabundant activity because of the mission, their wish to do personal activities after the day's work, the arrival of cargo ships or new astronauts who will cause time differences...

Headaches can occur with congestion due to elevated CO2 levels. A review on the relationship between headaches and CO2 level done by Law, et al. [14] showed a direct link in between the level of $\mathrm{CO} 2$ and the symptoms described by the astronauts. For each $1 \mathrm{~mm} \mathrm{Hg}$ increase in $\mathrm{CO} 2$, the odds of a crew member reporting a headache doubled. To keep the risk of headache below $1 \%$, average 7 -day $\mathrm{CO} 2$ would need to be maintained below $2.5 \mathrm{~mm} \mathrm{Hg}$ (current ISS range: 1 to $9 \mathrm{~mm}$ $\mathrm{Hg}$ ) [14].

The visual system is affected also in flight. This is the subject of much current research. It is among other things a

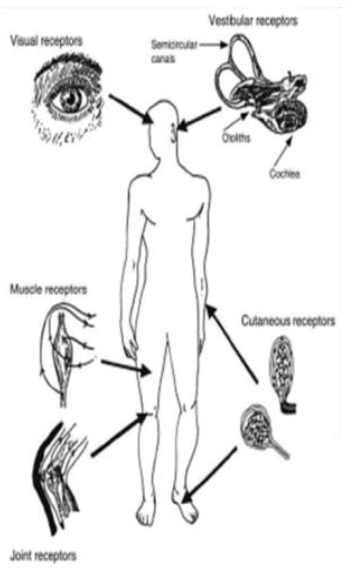

Diagram 
flattening of the eyeball and enlargement of the sheath of the optic nerve. Most of the time, astronauts do not suffer from any symptoms, except possibly a certain early presbyopia, which is usually arranged on their return to Earth. For the moment the mechanisms invoked are the modification of the fluid distribution with shift fluid towards the upper part of the skull thus also probably on the eyeball [15-17].

On the ENT plan, after already mentioning space sickness, which has a neuro-sensory origin, we can also see effects on the ears with either infectious or baro-traumatic ear infections rather due to EVA.

Hearing will also be affected, but more in relation to the actual environmental conditions than microgravity itself. There is a lot of noise on board the station because of the various computer equipment, treadmill on which the astronauts will run, water regeneration system, maintains air...

The digestive system is also affected in space, its involvement is probably not as visible as the muscle and bone involvement but it is translated by a feeling of fullness in the beginning of the flight with decrease of the appetite. At the moment the digestive flora is the subject of many projects for scientists. This flora would change mainly because of life in a closed environment [18].

Indeed, one of the other effects of life aboard the ISS concerns the confinement that will first have a psychological impact. Astronauts if they can communicate with families through their iPhone when they want of course outside of the experiments and communicate with ground crews have no contact outside the teammates and this for 6 months of their mission.

To end as the station will fly over the globe.. Every 90 minutes will have an alternation day night and all hormonal physiology may be disturbed.

Indeed, the hormones are secreted at specific times of the day (cortisol in the morning at 8 am and melatonin at dusk.

To counteract all these effects due to the dangerous environment a multitudes of actions have being taking and they are called countermeasures [19-23].

The best is to be able to prevent but as we saw from the previous chapter it is impossible if we go to space to avoid, radiations, microgravity and change in chronobiology.

The best preventive way is of course the process of the selection of the astronaut. It cannot prevent the effect of the environment but of course having somebody completely healthy and after a hard psychological selection it should minimize the risk of having an acute problem. Of course the selection dosen't prevent any incident as for human on Earth but if you already have medication or surgery it is already a fair condition which might drive to a bigger problem.
The best known countermeasure is the sport [19-23]. And to avoid to lose too much bone and muscle it has been established since the beginning of the space flight that astronauts have to practise $2 \mathrm{~h}$ daily sport activity. This is to the goal here but the activity will be adapted to the phase of the mission and because of the lack of gravity doing treadmill must be performed with a harness to reproduce tension on the body so from the beginning until the end of the mission the goal of the trainer will be to increase regularly the power so that the astronaut after the 6 months in flight has not lose too much. Three type of sprit will be done on board the station, the cyclo-ergometer, the treadmill both of those activities will increase or better stabilize the aerobic activity while the new ARED (Advacnce Resistive Exercise Device) will train the strength $[22,23]$.

To counteract the space adaptation syndrome (SAS) the use of medication has shown to be really efficient as it is on ground for the space motion syndrome [24-28]. Different medications exist it depend on the activity of the astronaut during the ascention to the station and it depend on the practised of the flight surgeon as well. But these medications will be tested on the ground to ensure they are efficient and they do not have secondary effect. Most of these medications are well known to decrease the level of vigilance it is what it has to be discussed astronaut and physician together.

In the past some tests have been done and thought to be efficient in prevention of the SAS but finally it seems not the case. It seems difficult too predict who will be sick or not? So only the Russian partners are still doing the tilt test and rotating chair to train the astronauts. Some of the European astronauts are doing it in the last 15 days prior to the launch during the quarantine phase but it is difficult to say if this helps or not.

Of course during the flight some medical exam will be regularly done to check the health of the astronaut, weight, blood pression, ears check with audiology (once per month), exercise stress test, eyes exam (visual acuity, questionnaire to check symptomas, ultrasound, fundoscope, and OCT (Optical Coherence Tomography) to check the retina have been reinforced since the discover of the SANS (spaceflightassociated neuro-ocular syndrome).

And a private medical conference will be done $15 \mathrm{mn}$ per week with the flight surgeon to discuss on all medical problem and more ... A private psychological conference is organised every two week. And the most important for the astronaut is the family conference one per week for one hour if possible.

\section{The spin-offs of space medicine for the earthlings}

Indeed, at a time when inequalities between developed and underdeveloped countries are far from being resolved, many people are tempted to tell us that it would be wiser to "keep this money to help the most disadvantaged". Politically, it is 
actually more complex and we will not prevent this discipline.. It is important at the international level that France and especially in this context Europe knows how to keep its place and therefore continues to evolve spatially.

But this spatial research allows us to evolve on many points. In fact, on the medical front, the first space flights allowed the development of various materials that are still used today, the holter, the ultrasound system. Space allows us to innovate by developing miniaturized tools, easy to use and robust are these various points that are fundamental for space and then we will use them on Earth [29].

From the medical point of view, we have seen that all human body systems are affected by microgravity and finally give the impression that astronauts have accelerated in space, which has become a tool for studying the effects of aging. Above all, it is an opportunity to develop countermeasures to overcome these effects of aging. But this is a major challenge given the aging of the population.. Develop drugs to fight against osteoporosis find new tools to allow further rehabilitation in the astronaut will also be useful for the elderly living on Earth.

Space will help to develop exerciser more enjoyable for the community. The problem of drugs if it is really efficient on osteoporosis as shown with biphosphonate is that it can be really a problem for astronauts because some of these drugs can increase the risk of kidney stone which is a real stopper for an astronaut [30,31].

The exerciser team try to find new tools with combination of endurance, virtual reality. Of course doing $2 \mathrm{~h}$ sport per day can be a long time if you don't like it so the need to increase the level of acceptability will be very good. For example during has flight Timothee Peake could run in the same time as the people in London during the marathon.. This was challenging for him and make fun.. It would be much more appreciated if sport can be done much more in that way, not alone..

Of course if such device a good on space station can be very nice on Earth for the people and notably the young ones who sometimes don't do sport at all.

Apart from the tools or drugs [32] developed, the scientific studies carried out at the astronaut are of a considerable contribution to understand the physiology and from the comprehension of the behavior of the human body one will be able to understand why this happens like that and so help more finely and find the right tool or good countermeasure.

Another very important component at the moment of the impact of the study of space on the human body is represented by obesity and the risk of developing diabetes.

Indeed apart from being a good model of aging, the space will trigger expensive astronaut after a mission even shortterm a tendency to hyperinsulinemia and even obesity.
Obviously since astronauts are vigilantly monitored before during and after their mission they do not trigger this pathology but we thus see the link with our new western lifestyles, fast food consumption and inactivity and this thus has a considerable impact on current societies (even very sedentary young people, generation Mac Do).

After the first phases of the space age that allowed us to see that the man could really adapt to this new environment despite some side effects, we started to work on long-term missions: 6 months. If 6 months is a long time in the life of a man, these 6 months aboard the station, the umbilical cord with the Earth is not broken and if a medical accident occurs we have two solutions to the problem. Either we can help the astronaut on board by guiding him with all the medical procedures he has learned if the pathology remains accessible and stable. In the opposite case the simplest solution is to repatriate the astronaut. We know that in a few hours we can bring astronauts back. To be safe and bring them safely 2 to 3 days would be safer, we stabilize the astronaut and send him back.

For interplanetary missions, take the example of a trip to Mars, there will be no more constant communication with the Earth so impossible to talk with the astronaut. This means that they will have to be much more autonomous ... and why not have a doctor or even better a surgeon on board.

The different researchers have a colossal and exciting work to develop tools that will allow an astronaut to know what he has pathology and how to heal. And this is where many artificial intelligence projects are developing and look very promising for the future.

This should also have direct spin-offs for us Terrans.

When we talk about space we often think of human flight but this is only a small part of the domain. Indeed satellites are also a great help and the various space agencies have shown their expertise in robotics. For example, many epidemiological studies will use these tools. The big advantage is that these satellites do not require sending the man into space and therefore it represents a lesser blow and less risk... (Figure 3).

For example, the gathering of information, for example the cross-referencing of environmental observation data by satellites (or remote sensing) with ground-based health data, makes it possible to establish models for predicting the risks of epidemics.

The use of satellite imagery is also a real technological advance to combat malaria, Rift Valley fever, yellow fever, dengue ... in developing countries.

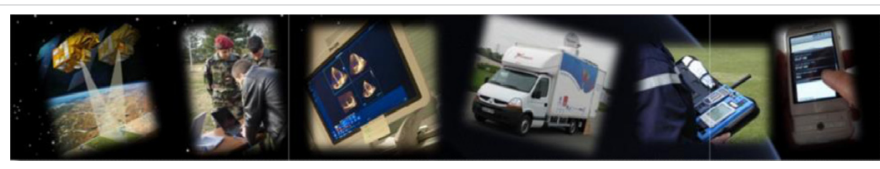

Figure 3 
From the space station they have a very good view on the world and we can see with all the pictures taken by the astronauts that they are really useful. Some projects are under development to help in following the catastrophic event like tsunami.. Why? Because the ISS is able to pass few time in a close frame time on the same area and see the changes. Because as well the quality of pictures taken are really good they are sometimes even better than the one taken by the space telescope. So nowadays a lot of project are using the pictures made by the astronauts $[33,34]$.

MEDES is involved in various projects in the establishment of epidemic surveillance networks in order to curb these plagues around the world. Thus, various projects have emerged in Senegal, South America, Burkina Faso, Niger and French Guiana [35-37]. At the space clinic, many projects are carried out to develop either molecules or countermeasures for the purpose of space, but because of the theme aging allow us to hope for a use for us land (Figure 4).

Within the framework of these themes, the ERISTO and ADOCQ projects have demonstrated the benefit of the 3D technique for assessing the quality of the bone (3D peripheral Quantitative Computed Tomography). These techniques represent a hope for the detection of osteoporosis because unlike the DEXA, which remains the gold standard for measuring bone density, this new tool allows a much finer and closer study of reality.

In terms of obesity, it has been shown that astronauts in space have a change in their insulin metabolism and are more likely to become diabetic. Nutrition is monitored by the Astronauts, and as part of Thomas Pesquet's Proxima mission, a nutrition monitoring tool was developed, funded by CNES. The principle is simple and uses an iPad tool that owns astronauts on board. At each meal the astronaut will have the live amount of calories and essential macronutrients ingested which allows him to manage without waiting for the report provided by the nutritionist once a week. We can imagine this kind of tool for at-risk patients, particularly sedentary young children of the MacDonald generation ... managing your own food intake with a user-friendly tool is certainly part of the combination of treatment and recovery. Physical activity (Figure 5).

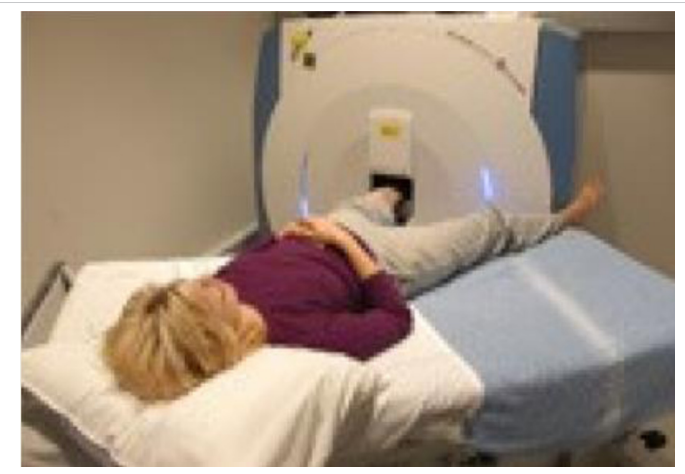

Figure 4

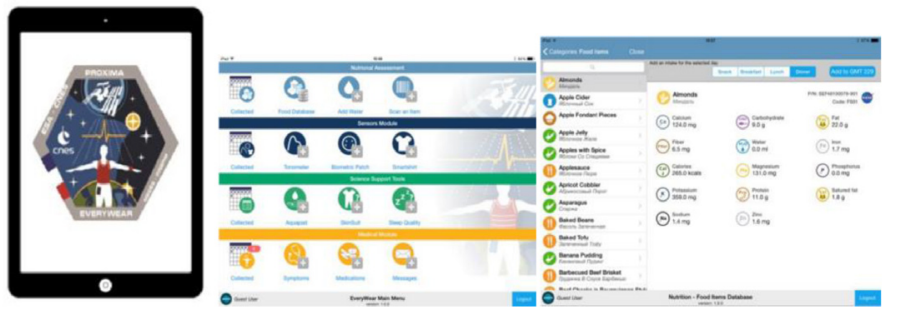

Figure 5

Another important area which shows the interest of space for community is the communications. Some project with students have been developed to help the school in many areas. For example it is well known that the astronauts will have specific time among the 6 months in such projects with school. The goal can be to explain to the young how does that work in space. But it can be as well to have a common project like growing plant in the same way and time the student can learn about the nature... Another type of project can be focused on sport. As said previously children become more and more sedentary so they have a good example with the astronauts and the school can implement new sport fitness like it is done on the ISS.

So through these simple examples we can already show how the tools developed for space are used for us Terrans. And it is always good to finish with this message of hope ... the conquest of space makes you dream as it has always been the case. Students of all ages are very motivated by space, which develops their curiosity, their will to understand and why not one day to colonize another planet ... if we already know that for us adults it seems unlikely that tomorrow we Departures to these unknown areas, for children all hope is allowed. And then, what we can remember from the flight of astronauts and in particular the testimony of Thomas Pesquet, "even if we know that our planet Earth is suffering and that we must protect it, the fact of seeing it in its entirety in both so beautiful and frail, can only encourage us to do everything to protect it and in any case makes us really aware of our role as Terrans on the protection of nature.

To conclude we can say space still have a lot to improve but we still have a lot as human on ground to use from all the studies perfomed on board the ISS.

The next future of space will be really challenging because the astronaut will have to be really autonomus which is absolutely not the case now.

$S$ in the next following decades if we need to send human to interplanetary mission we will need to solve the radiations issue, as well as the bone issues.

All of these challenges are nowadays on the top level of the agencies who are working together to define the new tools.

It seems the benefits will be as well for the humanity. Aging, 
obesity are example which show us how they will improved by the new tools and a better understanding of all physiological changes impacted by space and microgravity.

Another really interesting progress is the remote and telemedicine care. It has been shown that surgery can be perfomed successfully with a non-surgeon but with the help of telerobotic and the real surgeon guiding the novice on the real site [38,39].

This is something we need to solve for interplanetary mission. Such tools has been developed and used with astronaut [40].

On the same level, surgery has been done in parabolic flight, so we know that all kind of medical practices can be done in space. The only mandatory things are to make sure that the subject, the patient and al tools are correctly restraint. of course all activities take more time and need to be train [41-46].

A new tools represented by 3D printing $[46,47]$ may be of great help as well. Few studies show what can be done even for bone would be useful for the astronauts in case of broken legs it will help to fix the bone....

So it may well be that the future of medicine will be without the physician ... or it will become easier to leave in an isolated area because of the development of all these new technologies (Figure 6).

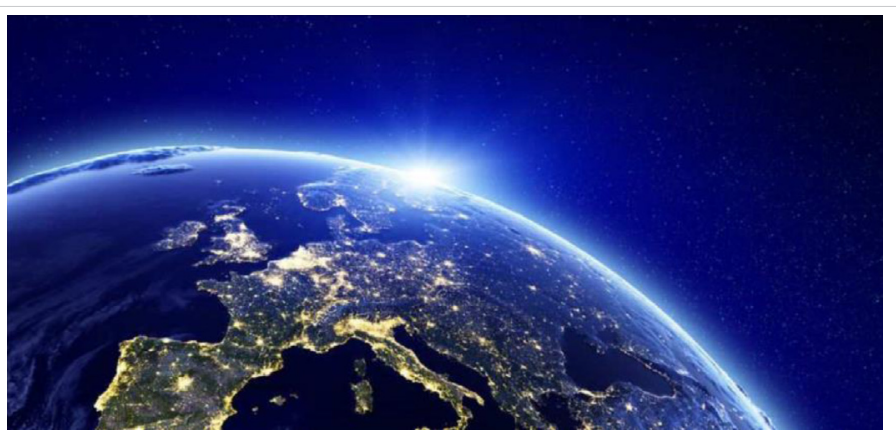

Figure 6

\section{References}

1. https://www.issnationallab.org/blog/international-space-stationbenefits-for-humanity-publication-released-today/

2. Nicogossian. Space Physiology and Medicine: From Evidence to Practice Springer 2016.

3. Med Volume B Pre-flight, In flight, and Ppost-flight Medical Evaluation Requirements for Long Duration ISS Crewmembers, SSP 50667 Volume B, Revision 3.2, 2014.

4. Godard B, Weerts G. Selection and follow up of the astronauts. Arch Mal Coeur Vaiss Prat. 2018; 3-10.

5. David Williams, Andre Kuipers, Chiaki Mukai, Robert Thirsk. Acclimation during space flight: effects on human physiology. CMAJ. 2009; 180: 1317-1323.

PubMed: https://www.ncbi.nlm.nih.gov/pmc/articles/PMC2696527/
6. ThirskR,Kuipers A,MukaiC, WilliamsD. The space-flightenvironment:the International Space Station and beyond. CMAJ. 2009; 180: 1216-1220. PubMed: https://www.ncbi.nlm.nih.gov/pmc/articles/PMC2691437

7. Maalouf M, Durante M, Forary N. Biological Effects of Space Radiation on Human Cells: History, ADvances and Outcomes. J Radiat Res. 2011; 52: 126-146..

PubMed: https://www.ncbi.nlm.nih.gov/pubmed/21436608

8. NASA Facts - Lyndon B. Johnson Space Center. Understanding space radiations. FS - 2002-10-080-JSC. 2002

9. Azizova TV, Bragin EV, Hamada N, Bannikova MV. Risk of Cataract Incidence in a Cohort of Mayak PA Workers following Chronic Occupational Radiation Exposure. PLoS One. 2016; 11: e0164357.

10. Smith SM, Heer M, Shackelford LC, Sibonga JD, Spatz J, et al. Bone metabolism and renal stone risk during International Space Station missions. Bone. 2015; 81: 712-720.

PubMed: https://www.ncbi.nlm.nih.gov/pubmed/26456109

11. Hughson RL, Robertson AD, Arbeille P, Shoemaker JK, Rush JW, et al. Increased postflight carotid artery stiffness and inflight insulin resistance resulting from 6-mo spaceflight in male and female astronauts. Am J Physiol Heart Circ Physiol. 2016; 310: H628-38. PubMed: https://www.ncbi.nlm.nih.gov/pubmed/26747504

12. Clement G. Fundamentals of space medicine. The neuro sensorysystem in space. $45-192$.

13. Gilles $\mathrm{C}$. Fundamentals of space medicine. The neuro sensory-system in space. Springer Edition N². 45-192.

14. Law J, Van Baalen M, Foy M, Mason SS, Mendez C, Wear ML, Meyers VE, Alexander D. Relationship between carbon dioxide levels and reported headaches on the international spacestation. J Occup Environ Med. 2014; 56: 477-83.

PubMed: https://www.ncbi.nlm.nih.gov/pubmed/24806559

15. Barger LK, Flynn-Evans EE, Kubey A, Walsh L, Ronda JM, et al Prevalence of sleep deficiency and use of hypnotic drugs in astronauts before, during, and after spaceflight: an observational study. Lancet Neurol. 2014; 13: 904-912.

PubMed: https://www.ncbi.nlm.nih.gov/pmc/articles/PMC4188436/

16. Mader TH, Gibson CR, Pass AF, Kramer LA, Lee AG, Optic disc edema, globe flattening, choroidal folds, and hyperopic shifts observed in astronauts after long-duration space flight. Ophthalmology. 2011; 118 : 2058-2069.

PubMed: https://www.ncbi.nlm.nih.gov/pubmed/21849212

17. Lee AG, Mader TH, Gibson CR, Tarver W. Space Flight-Associated Neuro-ocular Syndrome. JAMA Ophthalmol. 2017; 135: 992-994. PubMed: https://www.ncbi.nlm.nih.gov/pubmed/29527011

18. Patel N, Pass A, Mason S, Gibson CR, Otto C. Optical Coherence Tomography Analysis of the Optic Nerve Head and Surrounding Structures in Long-Duration International Space Station Astronauts. JAMA Ophthalmol. 2018; 136: 193-200.

PubMed: https://www.ncbi.nlm.nih.gov/pubmed/29327060

19. Marechal F, Ribeiro N, Lafaye M, Güell A. Satellite imaging and vectorborne diseases: the approach of the French National Space Agency (CNES). Geospat Health. 2008; 3: 1-5.

PubMed: https://www.ncbi.nlm.nih.gov/pubmed/19021103

20. Petersen $N$, Jaekel $P$, Rosenberger $A$, Weber $T$, Scott J. Exercise in space: the European Space Agency approach to in-flight exercise countermeasures for long-duration missions on ISS. Extrem Physiol Med. 2016; 5: 9.

PubMed: https://www.ncbi.nlm.nih.gov/pmc/articles/PMC4971634/

21. Loehr JA, Guilliams ME, Petersen N, Hirsch N, Kawashima S, et al. 
Physical Training for Long-Duration Spaceflight. Aerosp Med Hum Perform. 2015; 86(12 Suppl): A14-A23.

PubMed: https://www.ncbi.nlm.nih.gov/pubmed/26630191

22. Hackney KJ, Scott JM, Hanson AM, English KL, Downs ME, et al The Astronaut-Athlete: Optimizing Human Performance in Space. J Strength Cond Res. 2015; 29: 3531-3545.

PubMed: https://www.ncbi.nlm.nih.gov/pubmed/26595138

23. Smith SM, Heer MA, Shackelford LC, Sibonga JD, Ploutz-Snyder L, et al. Benefits for bone from resistance exercise and nutrition in longduration spaceflight: Evidence from biochemistry and densitometry. $\mathrm{J}$ Bone Miner Res. 2012; 27: 1896-1906.

PubMed: https://www.ncbi.nlm.nih.gov/pubmed/22549960

24. Kast J, Yu Y, Seubert CN, Wotring VE, Derendorf H. Drugs in space: Pharmacokinetics and pharmacodynamics in astronauts. Eur J Pharm Sci. 2017; 109S: S2-S8.

PubMed: https://www.ncbi.nlm.nih.gov/pubmed/28533143

25. Wotring VE. Medication use by U.S. crewmembers on the International Space Station. FASEB J. 2015; 29: 4417-4423.

PubMed: https://www.ncbi.nlm.nih.gov/pubmed/26187345

26. Diaz-Artiles A, Priesol AJ, Clark TK, Sherwood DP, Oman CM, et al. The Impact of Oral Promethazine on Human Whole-Body Motion Perceptual Thresholds. J Assoc Res Otolaryngol. 2017; 18: 581-590. PubMed: https://www.ncbi.nlm.nih.gov/pubmed/28439720

27. Golding JF, Paillard AC, Normand H, Besnard S, Denise P. Prevalence, Predictors, and Prevention of Motion Sickness in Zero-G Parabolic Flights. Aerosp Med Hum Perform. 2017; 88: 3-9.

PubMed: https://www.ncbi.nlm.nih.gov/pubmed/28061915

28. Russomano T, da Rosa M, Dos Santos MA. Space motion sickness: A common neurovestibular dysfunction in microgravity. Neurol India. 2019; 67(Suppl): S214-S218.

PubMed: https://www.ncbi.nlm.nih.gov/pubmed/31134912

29. Koskinen K, Rettberg P, Pukall R, Auerbach A, Wink L, et al. Microbial biodiversity assessment of the European Space Agency's ExoMars 2016 mission. Microbiome. 2017; 5: 143.

PubMed: https://www.ncbi.nlm.nih.gov/pubmed/29070062

30. Loehr JA, Lee SM, English KL, Sibonga J, Smith SM, et al. Musculoskeletal adaptations to training with the advanced resistive exercise device. Med Sci Sports Exerc. 2011; 43: 146-156. PubMed: https://www.ncbi.nlm.nih.gov/pubmed/20473227

31. Blue RS, Bayuse TM, Daniels VR, Wotring VE, Suresh R, et al Supplying a pharmacy for NASA exploration spaceflight: challenges and current understanding. NPJ Microgravity. 2019; 5: 14.

32. Vico L, Van Rietbergen B, Vilayphiou N, Linossier MT, Locrelle H, et al. Cortical and Trabecular Bone Microstructure Did Not Recover at Weight-Bearing Skeletal Sites and Progressively Deteriorated at NonWeight-Bearing Sites During the Year Following International Space Station Missions. J Bone Miner Res. 2017; 32: 2010-2021. PubMed: https://www.ncbi.nlm.nih.gov/pubmed/28574653

33. Barba D, Alabort E, Reed RC. Synthetic bone: Design by additive manufacturing. Acta Biomater. 2019; S1742-7061(19)30538-0. PubMed: https://www.ncbi.nlm.nih.gov/pubmed/31394295
34. Crawford IA. Astrobiological Benefits of Human Space Exploration. Astrobiology. 2010; 10: 577-87.

PubMed: https://www.ncbi.nlm.nih.gov/pubmed/20735249

35. Leblanc A, Matsumoto $T$, Jones J, Shapiro J, Lang $T$, et al. Bisphosphonates as a supplement to exercise to protect bone during long-duration spaceflight. Osteoporos Int. 2013; 24: 2105-2114. PubMed: https://www.ncbi.nlm.nih.gov/pubmed/23334732

36. Lleo MM, Lafaye M, Guell A. Application of space technologies to the surveillance and modelling of waterborne diseases. Curr Opin Biotechnol. 2008; 19: 307-312.

PubMed: https://www.ncbi.nlm.nih.gov/pubmed/18514503

37. Furlow B. New generation of satellites will shed light on respiratory disease. Lancet Respir Med. 2016; 4: 695-696.

PubMed: https://www.ncbi.nlm.nih.gov/pubmed/27599246

38. Sargsyan AE, Hamilton DR, Melton SL, Young J. Wyle Laboratories and NASA Johnson Space Center. The International Space Station ultrasound imaging capability overview for prospective users. Technical report. Houston (TX): NASA; 2006.

39. Pinsal. From weightlessness surgery to spatial surgery. e-mémoires de I'Académie Nationale de Chirurgie. 2010.

40. Garcia KM, Harrison MF, Sargsyan AE, Ebert D, Dulchavsky SA. Real-time Ultrasound Assessment of Astronaut Spinal Anatomy and Disorders on the International Space Station. J Ultrasound Med. 2018; 37: 987-999. PubMed: https://www.ncbi.nlm.nih.gov/pubmed/28960477

41. Reschke MF, Good EF, Clément GR. Neurovestibular Symptoms in Astronauts Immediately after Space Shuttle and International Space Station Missions. OTO Open. 2017; 1.

PubMed: https://www.ncbi.nlm.nih.gov/pubmed/30480196

42. Foale $C M$, Kaleri $A Y$, Sargsyan $A E$, Hamilton $D R$, Melton $S$, et al Diagnostic instrumentation aboard ISS: just-in-time training for nonphysician crewmembers. Aviat Space Environ Med. 2005; 76: 594-598. PubMed: https://www.ncbi.nlm.nih.gov/pubmed/15945407

43. Law J, Macbeth PB. Ultrasound: From Earth to Space. Mcgill J Med. 2011; 13: 59

PubMed: https://www.ncbi.nlm.nih.gov/pmc/articles/PMC3296555/

44. Arbeille $P$, Chaput D, Zuj K, Depriester A, Maillet $A$, et al Remote Echography between a Ground Control Center and the International Space Station Using a Tele-operated Echograph with Motorized Probe. Ultrasound Med Biol. 2018; 44: 2406-2412. PubMed: https://www.ncbi.nlm.nih.gov/pubmed/30093338

45. Arbeille P, Kathryn Z, Arnaud S, Elise A, Cedric De LP. Tele-Operated Echography and Remote Guidance for Performing Tele-Echography on Geographically Isolated Patients. J Clin Med. 2016; 5: 58. PubMed: https://www.ncbi.nlm.nih.gov/pmc/articles/PMC4929413/

46. KirkpatrickAW, McKee JL, Tien CH, LaPorta AJ, LavellK, et al. Abbreviated closurefor remote damage control laparotomy in extreme environments: A randomized trial of sutures versus wound clamps comparing terrestrial and weightless conditions. Am J Surg. 2017; 213: 862-869. PubMed: https://www.ncbi.nlm.nih.gov/pubmed/28390649

47. Hassan MN, Yassin MA, Suliman S, Lie SA, Gjengedal H, et al. The bone regeneration capacity of 3D-printed templates in calvarial defect models: A systematic review and meta-analysis. Acta Biomater. 2019; 91: 1-23. PubMed: https://www.ncbi.nlm.nih.gov/pubmed/30980937 